\title{
Normas, técnicas, trocas: Telefónica-Telmex e a Associação Telecomunicações- Televisão no Brasil
}

\section{João Damasceno Martins Ladeira}

Doutor; Universidade do Vale do Rio dos Sinos

joaomartinsladeira@gmail.com

\section{Resumo}

Este artigo analisa um aspecto na extensa reorganização do sistema audiovisual no Brasil contemporâneo: a progressiva presença de empreendimentos de telecomunicações em atividades de televisão segmentada. Aborda-se a questão, parte da reconfiguração do broadcast, como um aspecto particular de convergência. Identifica-se de que modo operações historicamente ligadas à indústria cultural se tornam apenas um entre os demais envolvidos com o audiovisual. A fim de apreender esta associação, discute-se a institucionalização da presença de Telmex e Telefónica em nosso país através da atuação de ambas em atividades de cabo e satélite. A partir de uma perspectiva que busca contribuir para os estudos de televisão segundo a proposta da arqueologia da mídia, foca-se no sistema de dispersões em curso, associando regulamentações jurídicas, tecnologias de comunicação e negociações materiais, abordadas como um processo descontínuo.

\section{Palavras-chave}

Estudos de televisão. Arqueologia da mídia. Convergência.

\section{Introdução}

Questão relevante para o campo da comunicação, o tema da convergência midiática se instituiu com foco nos efeitos proporcionados, sobre as mídias tradicionais, pela digitalização. De fato, intensa atenção se depositou na reformulação dos conteúdos distribuídos pelos meios convencionais. A centralidade do hipertexto como uma estrutura capaz de reconfigurar o formato linear das mídias (LÉVY, 1990, 1997); a hibridização de modos de vida a partir do progressivo contato do homem com a tecnologia, transformando a ele próprio 
devido à sua progressiva dependência destes dispositivos (SANTAELLA, 2004); o caráter instável do software, aberto à constante renovação de suas próprias capacidades e à sistemática reorganização dos produtos que dele dependem (MANOVICH, 2013); todos foram temas tratados. 0 debate tem sido amplo, à exceção de um tópico.

0 ponto deixado de lado se refere à discussão não sobre os produtos de comunicação em si, mas sim ao debate em relação à infraestrutura responsável por permitir a própria circulação de qualquer conteúdo. Esta problemática permite enxergar um dado relevante: certas organizações comprometidas de longa data com a indústria cultural - os serviços de televisão aberta e segmentada, em específico, e as atividades guiadas pela lógica do broadcast, em termos mais amplos - tornam-se progressivamente apenas um entre outros envolvidos com a confecção de cultura. A crescente participação dos empreendimentos de telecomunicações introduz um novo personagem neste cenário. A associação entre indústria cultural e telecomunicações, resultado da reestruturação dos serviços de televisão a cabo e satélite, aponta para um tipo pontual de conexão.

Convergência, em si, tornou-se um tema possível de encarar a partir de perspectivas bastante distintas. Neste sentido, o trabalho de Lopes e Gómez (2012), orientado pela expectativa de compreender de que modo procede a integração entre conteúdos e qual a lógica das associações construídas pelas organizações envolvidas em sua confecção, observou, em 11 países, os fluxos de televisão em 68 emissoras - 48 privadas e 20 públicas - com atenção à ficção e às formas diversas como veio a ser elaborada e apreendida. Uma investigação deste porte identificou a construção de uma programação global, organizada por instituições hábeis em agir numa dimensão igualmente internacional, em um cenário no qual se associam tecnologias das mais variadas.

Neste debate sobre convergência, trabalhos como os de Jenkins (2006) se mostraram igualmente relevantes. Para o autor, a ênfase recaiu sobre aspectos culturais. Por um lado, atenta-se para as características de públicos participativos ávidos por interferir em narrativas abertas e produtos interativos; por outro, observa-se as marcas de uma indústria disposta a intensificar o controle sobre seus bens, administrando a participação de usuários e impondo limites à forma como a relação com o público vem a ocorrer. Neste artigo, concentra-se menos nestes traços. Aborda-se um tema complementar: as condições históricas a partir das quais se constituem as infraestruturas de comunicação, ordenando a possibilidade para a circulação de conteúdo de qualquer tipo. 
Esta associação entre indústria cultural e telecomunicações decorre de fatores diversos. Depende da apropriação de questões jurídicas, inerentes aos debates que orientam a organização da indústria cultural. Envolve oportunidades presentes em transformações tecnológicas, visíveis na expansão das infraestruturas de comunicação hábeis em utilizar recursos que ultrapassam o broadcast. Engloba as transformações materiais capazes de criar empreendimentos aptos a agir de modo global. Apreender esta multiplicidade de normas, técnicas e trocas demanda uma visão histórica capaz de dar conta da fragmentação e da ruptura como centrais na constituição da realidade. Aqui, compreende-se esta questão a partir de uma visão centrada na ideia de arqueologia da mídia (HUHTAMO; PARIKKA, 2011; PARIKKA, 2012), parte de uma visada arqueológica sobre a história (FOUCAULT, 1969).

Em nosso país, a década de 2000 corresponde ao início do interesse por parte de empreendimentos de telecomunicações - operações que lidam com tráfego digital de dados e que tratam os registros mais distintos a partir de uma única lógica numérica - sobre atividades segmentadas de televisão. Na ordem instituída através de certo formato tecnológico, legal e produtivo, constrói-se o audiovisual como um recurso semelhante a qualquer atividade possível de envolver a circulação de informação. Este formato para distribuição transforma as telecomunicações em um eixo essencial para esta fração dos meios de comunicação - não mais especializados em registros físicos distintos, como havia sido no tempo em que se referiam ao som ou à imagem, mas sim constituídos segundo a mesma lógica responsável por ordenar dados no sentido estrito do termo (KITTLER, 1999).

Este texto se concentra na experiência que institucionaliza tal formato no Brasil: a presença, em nosso país, de Telmex, a partir de 2004, e de Telefónica, após 2006. Observar os eventos nos quais ambas se envolvem permite identificar uma lógica capaz de guiar a constituição do sistema audiovisual contemporâneo em um território. Para empreender a tarefa, a primeira seção deste texto expõe a questão teórica que orienta a arqueologia da mídia. Contrário à ideia de que a organização contemporânea dos meios ocorre devido ao desenvolvimento de determinadas opções encadeadas em linearidade progressiva, a discussão se concentra na dispersão percebida entre tecnologias, leis e mercados. A descrição deste processo, realizada na segunda seção, aborda as tentativas de Telefónica e Telmex em atuar no Brasil. Concentra-se na forma como ambas se esforçam por controlar técnicas previamente disponíveis, por um lado. Analisa-se o modo como constroem posicionamentos sobre a norma legal, por outro, retomando interpretações oferecidas no passado e tentando interferir na forma pela qual tais visões virão a ser retomadas no futuro. 


\section{Arqueologia da mídia: problemas e conceitos}

Debater a organização contemporânea dos sistemas de comunicação tem sido uma discussão que versa sistematicamente sobre computadores (LEMOS, 2002; LÉVY, 1990, 1997). Em um debate orientado por tal ponto de vista, a televisão se veria obrigada a se manter sempre numa posição lateral. Se a transformação nos sistemas de comunicação se refere apenas àquelas tecnologias de comunicação e informação mais óbvias; se tal questão se restringe a internet, às tecnologias móveis, a software e hardware; se assim for, a televisão se veria fadada a ocupar um espaço no contemporâneo apenas quando se versa sobre seus processos pontuais de digitalização, como a adoção de novos formatos de transmissão, ou sobre a possibilidade de introjetar a interatividade.

Diante das diversas transformações presenciadas pela televisão, tal perspectiva se mostra no mínimo limitada. A lógica da representação numérica corre mais a fundo, sem se limitar ao apagão analógico do broadcast convencional ou à participação do usuário. A reestruturação da indústria cultural ocorre não pela divisão entre um "antes" e um "depois", na espera pelo dia em que finalmente se discernirão os canais de retorno ou a televisão digital. Apreender este limite implica em questionar uma visão sobre a história que se concentra na oposição entre momentos antagônicos. A arqueologia, ao contrário, atenta para a possibilidade de entender uma dada realidade como constituída por diversas instâncias descontínuas, como superfícies que se cruzam. Desta forma, torna-se difícil perceber um dado fator como determinante para estruturar uma ordem.

Compreender a arqueologia da mídia implica em perceber como este debate se insere no trabalho do autor responsável por instituir a perspectiva arqueológica - Foucault (1969). Eixo central da discussão reside no debate sobre os processos de ordenação dos objetos que constituem a realidade. 0 projeto da arqueologia depende de uma compreensão particular sobre a organização da história, pressupondo que ela se estrutura não pela ação dos sujeitos. Na verdade, sua ordenação ocorre exatamente a despeito deles.

Ao abandonar a expectativa sobre a centralidade do sujeito, institui-se uma questão essencial: em que termos a história se constitui? Propõe-se que qualquer configuração possua regras de organização (DREYFUS; RABINOW, 1983; GUTTING, 1989; SHERIDAN, 1980; SMART, 1985). Pensar em termos de tais regras implica em entender a constituição da realidade como consequência de relações subterrâneas, distantes da ingerência do sujeito, reduzindo a importância da consciência. A arqueologia enfatiza tópicos impossíveis de pensar quando se considera que os interesses deste personagem ocupem o centro do desenvolvi- 
mento histórico. Em sua natureza, tais regularidades se referem às condições de possibilidade para, a partir de movimentos localizados no interior destas regras, instituir qualquer ordenamento. Esta estruturação da realidade se pensa nos homens, sem ser criada por eles: as categorias de pensamento se tornam produtos elaborados alhures.

Regras se definem como uma prática, cuja ordenação implica em seu uso. 0 interesse reside em compreender o seu emprego. No entanto, o processo por meio do qual se ordenam os objetos ocorre não segundo lógicas abstratas localizadas fora da história. Ao contrário, interessa exatamente o movimento em seu interior, na expectativa de compreender como ela própria pôde vir a se formar. Regras, na verdade, surgem como uma tessitura complexa, mantida pela ordenação construída pelos múltiplos fios a partir dos quais este tecido se sustenta.

Esta percepção relativa a regras se desdobra na concepção sobre outro tema chave para a arqueologia: a formação dos objetos. Relevante se torna o processo no qual tais regras de formação indicam a possibilidade deste próprio objeto ter a chance de emergir, pressupondo sua inexistência prévia. A natureza concreta destes objetos será a mais variada. Nas discussões empreendidas por Foucault, a loucura; a medicina; as ciências da linguagem, da vida e da riqueza; todos são objetos. Compreender as fronteiras de tais objetos e os limites que os separam uns dos outros se torna tarefa que demanda uma metodologia específica.

A constituição de um objeto ocorre por meio de um processo de diferenciação em relação aos demais. Não se pode definir a organização de uma atividade a partir dos critérios propostos pelos envolvidos com ela própria. A arqueologia critica uma postura na qual se poderia crer que uma "revolução" em um dado conhecimento procede pela "descoberta" de um novo "avanço", observando de outro ângulo uma realidade previamente existente, mas até então apenas obscura. Ao contrário da ação capaz de substituir uma perspectiva anterior, "incorreta", por outra, mais "acertada", busca-se perceber as alterações proporcionadas pelo surgimento de novos objetos como desdobramento de outras combinações nestas regras de formação.

Supor um dado conhecimento como "superado" ou descartar certa disciplina como "ultrapassada" implica em imaginar a constituição do conhecimento como algo possível de se acumular de forma encadeada. Esta visão implica em pensar um objeto como uma unidade sequencial. A arqueologia, ao contrário de coordenar um objeto a partir de um ponto de origem responsável por guiar o seu desenvolvimento, supõe a sua dispersão. No lugar de tal 
encadeamento, tenta-se entender a constituição de um objeto como consequência da conexão entre elementos dos mais diversos. Ao se abandonar a expectativa de identificar algum ponto original, capaz de organizar uma direção única, deixa-se também de esperar algum destino final.

Pensar tal dispersão permite apreender as associações das quais cada objeto decorre. A partir desta perspectiva, a mídia surge como um objeto cuja formação depende de elementos em ruptura e descontinuidade, como o trabalho de Zielinski (1994) expõe. Implica a tecnologia, sem a qual a possibilidade de armazenamento e circulação não seria possível. Afinal, a delimitação dos meios para broadcast havia comportado ferramentas para transmissão, por um lado, e instrumentos capazes de armazenar a imagem em movimento, por outro. Ambos recorrem a técnicas que implicam desde a telefonia e a telegrafia (importantes para a televisão), até a fotografia (relevante para o cinema).

Refere-se também à ciência, a partir da qual a tecnologia do broadcast veio a se institucionalizar. No momento em que se organizam as explorações iniciais com som e imagem, depende-se tanto da experimentação com a eletricidade quanto das técnicas de percepção a partir do corpo. Em um plano distinto, diz respeito à cultura, principal recurso a ser instrumentalizado. A ênfase, nestes termos, consiste na organização dos públicos, parte do processo de constituição das massas. Na ausência da diferenciação produzida por tal agrupamento, a mídia se mostraria um tema carente de positividade. Sua unidade decorre da prática capaz de unificar esta diversidade. Frente à pluralidade de associações, se tornaria difícil identificar alguma gênese.

Neste texto, avista-se este panorama amplo, concentrando-se, porém, em uma questão pontual. Atenta-se para a diferenciação, em relação aos serviços de broadcast, de atividades de televisão global, com atenção às normas, técnicas e trocas que estruturam este processo. A problemática jurídica, presente no tipo de autorização para aquisições internacionais; a questão econômica, decorrente da operação de empreendimentos globais capazes de intervir em vastas dimensões de espaço; a dimensão tecnológica, visível na diversificação do audiovisual a partir do cabo e do satélite; todas estas três superfícies adquirem unidade mediante a prática relativa às regras de formação em operação. Descrever historicamente este processo ocorre na próxima seção. 


\section{O sistema audiovisual no Brasil contemporâneo: indústria cultural e telecomunicações}

As tentativas de Telefónica para, no Brasil, atuar na indústria cultural se iniciam em junho de 2006, ao apresentar a Agência Nacional de Telecomunicações (Anatel) uma solicitação para operar um serviço de direct to home (DTH). Necessário em qualquer ocasião, o processo envolve a análise da agência reguladora e a decisão sobre a legalidade da solicitação. 0 pedido possui um sentido bastante específico. Os limites impostos a operações de cabo haviam transformado o DTH em uma oportunidade importante. Satélites haviam se tornado a única técnica que corporações internacionais podiam controlar sem ter de lidar com barreiras regulatórias. A solicitação, porém, dá início a uma intensa discussão pública, a primeira entre outras que se presencia em nosso país durante a constituição do envolvimento de empreendimentos de telecomunicação com a indústria cultural.

Momento igualmente chave para a tentativa de Telefónica em atuar na indústria cultural brasileira se torna o anúncio da compra da TVA em outubro de 2006 por $\mathrm{R} \$ 922 \mathrm{mi}$ lhões. Devido mais uma vez a uma discussão regulatória, o acordo se transforma numa operação com ainda maior complexidade. A tentativa de associar estas duas tecnologias, cabo e DTH, indica o interesse de Telefónica em agir no Brasil. Em um caso com circunstâncias inéditas, a solução legal ditada pelos órgãos reguladores vai definir o modelo para este tipo de associação entre telecomunicações e indústria cultural. A partir das escolhas adotadas pelas agências envolvidas, estrutura-se a possibilidade de criar um vínculo que procede segundo uma lógica de conexão guiada pela associação entre ambas as atividades.

Durante a discussão, constrói-se certa dinâmica, indicando um padrão. Uma primeira contraposição pública à operação de DTH ocorre em agosto de 2006. Na ocasião, alguns representantes da Associação Nacional de Televisão por Assinatura (ABTA), anunciam a possibilidade de encaminhar a Anatel um pedido visando impedir a concessão. Em seu argumento, tentam caracterizar o pedido de Telefónica como um risco para os demais operadores de televisão segmentada já em atividade. A ABTA solicita que se entenda a solicitação para DTH como um pedido possível de enquadrar nos limites impostos pela Lei no 8.977, de 6 de janeiro de 1995, a Lei do Cabo, com cláusulas estritas sobre a impossibilidade de empreendimentos de telecomunicações atuarem na indústria cultural (POSSEBON, 2007a).

Indispensáveis para a negociação com um empreendimento de televisão segmentada, estas normas indicam um tema com o qual Telefónica, como qualquer outra operação envolvida na superfície de trocas, não poderia se eximir de lidar. Resultado de decisões pré- 
vias, tomadas durante a regulação das atividades de telefonia em nosso país e instituídas em legislações, normas e resoluções, o debate jurídico, por sua vez, surge como uma dimensão que, na condução de uma luta capaz de ultrapassar o âmbito de uma aquisição específica, colabora na ordenação da maneira como um sistema audiovisual vai se constituir no Brasil. 0 resultado obtido depende de questões introduzidas no embate pela ABTA, transformando a relação de ambas em um tópico necessário de descrever.

A compra de TVA, obedecendo às normas legais, ocorre de forma fragmentada. Frente à ausência de limites na regulação, Telefónica adquire 100\% da operação de multichannel multipoint distribution service (MMDS). Seguindo os limites para participação estrangeira definidos pela Lei no 8.977, de 6 de janeiro de 1995, compra 49\% das operações de cabo nas cidades em que TVA atuava, com exceção de São Paulo. Circunstâncias específicas a esta cidade tornam-se de central importância. Em julho de 1998, durante a privatização do Sistema Telebrás, Telefónica, junto com outros sócios, haviam adquirido, por US\$ 4,96 bilhões, a Telesp, empresa de telefonia fixa do Estado de São Paulo (BALBONTÍn, 2005). A atuação de Telefónica em telefonia básica se torna um dos argumentos mais importantes na condução do caso TVA. Tanto a Lei no 9.472, de 16 de julho de 1997, Lei Geral de Telecomunicações, quanto os contratos de concessão impediam as operadoras de telecomunicações de possuir, no Estado em que detinham autorização para telefonia fixa, o controle sobre outra atividade. 0 embate jurídico e material versa, assim, sobre duas facetas da concentração de propriedade.

Devido a este limite, a compra de Telefónica se restringe, na cidade de São Paulo, a 19\% da TVA. Seguindo a Resolução 101/99 da Anatel, a participação surge como valor limite, que indica a ausência de controle de Telefónica sobre a operadora de televisão segmentada. Ao obedecer à restrição, a compra cumpriria a cláusula 14.1 do contrato de concessão para telefonia fixa (BRASIL, 2006). São precauções de Telefónica para evitar uma luta jurídica, que, devido a um cruzamento de questões, mostra-se impossível de burlar.

A oposição pública da ABTA, uma associação que, contraditoriamente, representa os diversos empreendimentos de televisão segmentada, inclusive Abril, chega já na primeira hora. Logo após o anúncio da compra, a Associação chama a atenção em uma nota para os riscos decorrentes da conexão dos serviços de cabo e MMDS com a concessão de telefonia fixa em São Paulo (FUOCO, 2006). Em março de 2007, a ABTA apresenta ao Conselho Administrativo de Defesa Econômica (Cade) uma medida cautelar, solicitação enviada antes mesmo da Anatel se manifestar sobre o caso. A Associação pede que, previamente à análise da 
fusão, encerrem-se as ações conjuntas, já em curso, entre Telefónica e TVA. A necessidade de tal postura, defende-se, decorreria de um possível risco para a concorrência, não apenas no presente, mas também no futuro. 0 argumento da ABTA se refere ao controle possível de exercer a partir da ligação entre estas redes fixas de telefonia local e as tecnologias de cabo e MMDS. Frente à possibilidade, a Associação aponta a chance de Telefónica se transformar em um empreendimento impossível de competir.

A discussão sobre o acordo remete, em uma postura adotada em outras ocasiões, a uma probabilidade sobre um fato ainda por acontecer. A compra de TVA no presente impediria, por exemplo, que outro possível interessado se decidisse posteriormente pela aquisição da operadora no futuro. A este tema se associa uma discussão sobre o MMDS. Única concessão deste tipo na região, representaria uma possibilidade para, como mais uma probabilidade para o futuro, outro concorrente dar início à atuação em São Paulo (ABTA..., 2007).

Inicialmente uma técnica restrita à difusão apenas de audiovisual segmentado, transformações técnicas permitiam relacionar o MMDS a tráfego de dados em sentido mais amplo. A frequência disponível, de 2,5 GHz, com aproximadamente $190 \mathrm{MHz}$ de largura no espectro, tornara-se, a partir dos primeiros investimentos da Intel em 2004, um recurso útil para seu uso em redes de transmissão Wi-Fi. Como consequência, estes serviços sem fio poderiam se equiparar às técnicas para distribuição de dados através do cabo. As frequências para MMDS então controladas por Abril consistiam em um recurso escasso: a Anatel havia distribuído cerca de 25 delas durante os primeiros momentos da organização da televisão segmentada no Brasil, sem a expectativa de voltar a oferecê-las (POSSEBON, 2009).

0 caso Telefónica-TVA relaciona dois debates. Tanto na discussão sobre a associação entre outorgas para MMDS e cabo quanto no debate sobre os serviços de telefonia fixa, versa-se sobre a técnica, questão dotada de positividade em certo momento histórico. Ao mesmo tempo, debate-se o tópico da concorrência, tema marcado por uma noção de interesse público. Como um elemento do sistema de dispersão, esta segunda questão se coordena com a primeira, tornado ambas parte significativa da possibilidade de conexão em processo de constituição. 0 resultado se torna uma discussão sobre o futuro.

Após as ofensivas da ABTA, a TVA retira juridicamente da Associação a possibilidade de intervir nas decisões regulatórias. Em abril de 2007, a operadora obtém, junto a 40ํㅡara Cível de São Paulo, uma liminar contra a ABTA, impedindo que ela voltasse a se manifestar sobre a fusão. Em seu pedido, defende a falta de legitimidade, por parte da Associação, em contestar a compra. Argumenta-se: dada a sua constituição, a ABTA se via obrigada a posi- 
cionar-se imparcialmente em embates públicos relativos a seus integrantes (TVA..., 2007). Também em abril de 2007, o Cade nega a medida cautelar apresentada pela Associação. Contudo, embora a Anatel não identifique riscos irreversíveis, condição para encerrar a fusão, retoma o tema do MMDS em seu parecer, reforçando a atenção sobre esta técnica.

Finalmente, a Anatel autoriza a operação em julho de 2007. A definição da Agência sobre a compra mantém alguns temas introduzidos pela ABTA. No fim, não se descola completamente da direção proposta pela Associação. Mantém-se a posição sobre as possíveis consequências do controle sobre a TVA em São Paulo. Na interpretação da Anatel, se atenderia o contrato de concessão somente se, além de se eximir em expandir a sua participação acionária para além de 19\%, a Telefónica abrisse mão de exercer poder de veto. Novamente, traz-se a Resolução 101/99 ao debate: na apropriação da Agência sobre o texto, controle decisório também se caracteriza através de poder de veto (POSSEBON, 2007b).

A compra de TVA por Telefónica não representa uma ação isolada. Ocorre como parte de um movimento de consolidação responsável por permitir a negociação com operações das mais diversas. Trata-se de um momento no qual, em um curto espaço de tempo, empreendimentos de televisão segmentada mudam de mãos. Especialmente significativo vem a ser, em outubro de 2006, a aquisição, pela Net, de Vivax, uma operadora que se tornara relevante em pouco tempo. Atuando no interior do Estado de São Paulo, região de importância econômica, Vivax se expandira de forma autônoma, recorrendo à compra de operadoras endividadas e à abertura de capital. A associação entre Net e Vivax, dois serviços de cabo agindo em regiões nas quais suas outorgas não se sobrepunham, torna a discussão regulatória decididamente mais simples (LADEIRA, 2014; POSSEBON, 2006).

Em dezembro de 2007, a Net anuncia a compra de BigTV, uma operadora com atuação em 12 cidades de quatro Estados: São Paulo, Paraná, Alagoas e Paraíba. Nestas últimas duas localidades, a compra da BigTV garantia o acesso da Net a outorgas para prestar serviços em capitais. Em agosto de 2008, a Net compra a ESC 90, uma operadora de televisão e internet banda larga, com atuação em Vitória (ES). Com a operação, Net garante a atuação em todas as capitais das regiões Sul e Sudeste. A BigTV era até então controlada por Alusa, uma empresa dos setores de eletricidade, telecomunicações, engenharia e construção civil. A ESC 90 era propriedade de Escelsa, uma operadora de energia. Ambos eram serviços não diretamente ligados à indústria cultural, negociando suas atuações prévias na atividade. As decisões de venda permitiam a expansão da convergência de atividades entre televisão segmentada e empreendimentos de telecomunicações (MERMELSTEIN, 2008). 
Não apenas empreendimentos internacionais se encontram às voltas com a necessidade de definir os termos responsáveis por guiar a associações entre telecomunicações e indústria cultural. Em julho de 2006, Telemar adquire WayTV, um serviço de televisão a cabo em operação em Minas Gerais. Trata-se de uma região na qual Telemar possuía, como Telefónica em São Paulo, contratos para telefonia fixa. Como no caso TVA-Telefónica, a compra demanda interpretações por parte dos órgãos reguladores, pautando do mesmo modo as decisões futuras sobre a questão ("TELEMAR...", 2006). Seguindo critérios que retomavam os contratos de concessão para telefonia fixa, a Anatel nega a operação em março de 2007.

Telemar recorreria da decisão, e a Anatel reavaliaria sua posição sobre a compra da WayTV. Para isto, contrapõe a Lei no 8.977, de 6 de janeiro de 1995, à interpretação sobre a telefonia fixa. A Agência recorre a uma das condições contidas no texto de 1995 para permitir a participação de empreendimentos de telecomunicações em atividades anexas dentro dos limites da região em que possuem concessões para telefonia fixa: a ausência de outros interessados. A WayTV havia sido vendida em um leilão no qual a Net havia se retirado ("ANATEL NEGA...", 2007). A decisão do Cade, em junho de 2008, impõe condições relativas exatamente à tecnologia de MMDS: até 2010, Telemar, que durante o processo muda a marca para Oi, não poderia, naquela região, adquirir operações de MMDS nem utilizar aquelas que já possuía ou explorar a frequência de Worldwide Interoperability for Microwave Access (WiMAX) (MAZZA, 2008b).

Do mesmo modo como fizera no caso Telefónica-TVA, a ABTA tenta intervir na decisão Telemar-WayTV. Também nesta operação, defende a ilegalidade de convergir operações de telecomunicações com serviços de televisão segmentada. Ameaça, frente à decisão favorável da Anatel, recorrer à justiça comum (ABTA..., 2006; PARENTE, 2006). A aquisição conduzida por Oi/Telemar consiste em um ato de um grupo local, cujos embates se restringem ao Brasil. As questões relativas a Telefónica remetem a lutas de outra ordem, com dimensão internacional. Do mesmo modo como havia procedido no Brasil, Telefónica coordena uma série ampla de ações que se referem à tentativa de participar na indústria cultural em regiões variadas. 0 mesmo ocorre com Telmex, principal acionista da Net, delimitando um enfrentamento entre tais empreendimentos, como um padrão repetido em oportunidades diversas (BALBONTÍN, 2005; MARISCAL; RIVERA, 2005).

No Brasil, os embates entre Telmex e Telefónica remontam a uma das primeiras e mais importantes ações da operação mexicana em nosso país: a aquisição da Embratel. A 
compra da operadora de longa distância havia decorrido de dificuldades enfrentadas por MCI, que assumira sua propriedade durante as privatizações de 1998. A decisão de MCI em negociar a Embratel ocorre como parte de questões mais amplas. Em julho de 2002, MCI dera início a seu processo de falência junto a cortes norte-americanas. A reestruturação, consequência de fraudes contábeis durante a década de 90, não impunha a obrigação de incluir suas atividades em outros países. Contudo, a MCI decidira negociar parte destas operações internacionais como forma de reduzir a sua dívida.

Em novembro de 2003, começa a busca de MCI por propostas pela Embratel. Em dezembro do mesmo ano, receberia três: de um consórcio identificado como Calais, formado por Telefônica, Telemar e Brasil Telecom e que contava com o apoio do BNDES; de Telos, fundo de pensão dos funcionários da Embratel; e de Telmex. Em abril de 2004, a Telmex compra 51\% de ações ordinárias por US\$ 400 milhões. A oferta realizada pelo consórcio Calais - mais elevada, no valor de US\$550 milhões - seria rejeitada devido a temores sobre possíveis restrições regulatórias futuras. Em ambas as propostas, o valor se mantinha abaixo do total de US\$ 890 milhões pagos por MCI em 1998, durante o processo de privatização (CARIELLO, 2004).

Em junho de 2004, através da aquisição da Net, concretiza-se o envolvimento de Telmex com a indústria cultural. A associação entre operações de telecomunicações e de televisão segmentada procede pela possibilidade desta operação de cabo se tornar um provedor de serviços de telefonia. A atenção de Telmex, concentrada nos recursos para tráfego de informações, refere-se na ocasião não às possíveis oportunidades para acesso a conteúdo, seja em termos da oportunidade de distribuir audiovisual controlado pela Net no México, seja na busca por inserir no Brasil conteúdo originário daquele outro país latino-americano. Seu foco se concentra no controle sobre a infraestrutura para cabo.

Conduzida apenas dois meses depois da aquisição da Embratel, a compra da Net, obedecendo aos limites impostos pela Lei no 8.977, de 6 de janeiro de 1995, implica na aquisição de 49\% de ações, mantendo a prerrogativa de obter o controle a partir de uma possível alteração na regulação, contudo. 0 endividamento da Net (que, em 2002, chegaria a suspender o pagamento de suas dívidas), assim como os sistemáticos prejuízos (responsáveis por impedir novos investimentos em expansão), tornam-se as principais motivações para a venda. Os serviços de cabo da Net, instalados em diversas cidades, passarão a ser utilizados para a venda de produtos de telefonia de uma forma que Telefónica, Brasil Telecom e Telemar, restritas às suas áreas de concessão, mostravam-se naquele momento incapazes de 
empreender. Subvertendo a organização prévia através da qual se ordenou o sistema brasileiro de telecomunicações após as privatizações de 1998, uma operação da indústria cultural garantiria a possibilidade de negociar com serviços de telefonia (LOBATO, 2004).

Neste curto período, localizado entre 2006 e 2008, define-se a possibilidade de associação entre indústria cultural e telecomunicações. A solicitação de Telefónica para o serviço de DTH seria aprovada pela Anatel em março de 2007. A partir daí, as experiências com televisão via satélite se expandem com a concessão de autorizações para o início de atividades de Embratel com satélites, em abril de 2008; de Oi, em setembro de 2008. Do mesmo modo que ocorrera com Telefónica, a distribuição de tais autorizações para as operadoras de telecomunicações envolve determinadas exigências. Seguindo obrigações impostas para serviços de cabo, os serviços de DTH transmitiriam canais da Câmara, Senado, Justiça e um serviço do Ministério da Saúde. Deveriam ao mesmo tempo doar dois mil pacotes, compostos por televisores, antenas e receptores, a ser instaladas em entidades escolhidas pelo Ministério da Saúde (MAZZA, 2008a; “OI É AUTORIZADA...”, 2008). A conexão entre telecomunicações e indústria cultural está pronta para se expandir, seguindo em uma direção cujos limites apontam para a identificação entre ambas.

\section{Conclusão}

Através de uma perspectiva arqueológica, descreveu-se a diferenciação de sistemas de comunicação anteriormente ordenados segundo a experiência típica aos serviços de broadcast, adotando uma lógica de organização que transforma o audiovisual em uma parcela das atividades de telecomunicações. Observou-se a coordenação de uma série ampla de temas, identificando estes suportes e descrevendo a sua articulação, no intuito de compreender a organização da história a partir da relação entre múltiplos pontos de apoio. Produzir um formato para a televisão característico às sociedades contemporâneas implica em congregar públicos diversos, cuja coesão depende de conteúdos igualmente variados. Se o audiovisual contemporâneo se afasta da dualidade entre individualização e massificação, esta diversificação ocorre não no vácuo: depende da uma infraestrutura sem a qual soaria difícil imaginar a sua constituição.

No Brasil, como em outras regiões da América Latina, os empreendimentos de telecomunicações foram relevantes para ordenar esta infraestrutura, explorando oportunidades previamente disponíveis, mas com uso até então aquém de suas possibilidades. 0 interesse na indústria cultural, operacionalizando estes recursos de um modo que em outras circuns- 
tâncias não havia se mostrado viável, rompe as barreiras previamente definidas entre ambas as atividades, mesclando-as. Em tais eventos, os empreendimentos de telecomunicações não se restringem às fronteiras nacionais. Dado o seu caráter de organizações globais, atuam em regiões muito variadas. Na América Latina, o embate entre Telefónica e Telmex implica em vínculos que ultrapassam o nosso país, estendendo-se desde a América Central até as nações mais ao sul: ações travadas em cenários pontuais decorrem, afinal, de interações mais amplas.

Sua definição, por sua vez, ocorre segundo um sistema de dispersão no qual operam temas caros às esferas técnica, jurídica e produtiva. Estes procedimentos lidam com a associação entre técnicas variadas, em que se conectam tecnologias para difusão de audiovisual, telefonia e tráfego de dados. Em um momento marcado pela necessidade de governar e administrar as relações nos níveis mais variados, delimitar a organização do vínculo entre indústria cultural e telecomunicações depende de decisões tomadas no âmbito regulatório. A expansão internacional de operações produtivas implica em aquisições. A entrada em novas regiões se vincula a múltiplas oportunidades: os programas nacionais de privatização; o abandono de países por corporações endividadas; a impossibilidade de sócios nacionais manterem os investimentos necessários. Relativas ao universo produtivo, estas aquisições demandam decisões por autoridades governamentais. Sua ação impõe obrigações ou mesmo inviabiliza processos. A oportunidade de intervir, introduzindo direções caras à lógica da regulação se torna uma questão importante de avaliar.

O sistema de dispersão presente na reorganização desta fração do sistema audiovisual no Brasil comporta o seguinte conjunto de fatores. Refere-se a relações capazes de permitir que decisões tomadas em outras regiões, distantes do Brasil, definam os rumos adotados em nosso país. Consiste na possibilidade de deliberações jurídicas intervirem na decisão sobre o resultado alcançado. Relaciona a tecnologia de difusão de audiovisual com a de telecomunicações, permitindo uma fórmula para a operação conjunta de ambos. Descrever de que modo estes elementos se associam, considerando a possibilidade, como regra, de permitir a constituição da experiência de conexão, surge como a tarefa que se pretendeu cumprir. Observar este desdobramento implica em apreender o conjunto de a priori históricos, instituindo novas experiências na formulação dos sistemas audiovisuais. As iniciativas aqui discutidas instituem parâmetros relevantes, a partir do qual diversas outras ações vão se pautar. 
Os fenômenos descritos, relativos a uma série de aquisições, em um embate recorrente com normas em vigor, deparando-se com a oportunidade de renovar dado recurso técnico, participam do contexto a partir do qual se constrói na diacronia o formato da televisão por vir. Não apenas por se tornarem os novos proprietários de empreendimentos à beira da falência, as telecomunicações se afirmam como um personagem essencial neste processo. Transformam-se na organização responsável por encaminhar a constituição das mídias contemporâneas em direção a um sistema integrado, baseado em tecnologias digitais.

Nos anos seguintes, ganharão popularidade os primeiros serviços over the top (OTT), distribuindo conteúdo através tão somente de redes digitais. Em pouco tempo, produtores convencionais de audiovisual publicam seus aplicativos para acesso aos acervos que controlam, rivalizando com estes novos difusores. Os serviços de infraestrutura para tráfego, aqueles mesmos que se tornaram proprietários tanto das operações de televisão segmentada quanto dos empreendimentos de telecomunicações, investem na adoção de tecnologias de fibras óticas, preparando um cenário inteiramente pautado pela difusão digital. Audiovisual por demanda, em redes com capacidade para ultra-alta definição, tende a se tornar, a partir de então, a regra. Originados em regiões centrais, tais eventos se repetem na semiperiferia por ações encaminhadas exatamente pelas operações aqui discutidas: Telmex e Telefónica.

A televisão do séc. XXI depende destes empreendimentos. Como um agente provocador, a digitalização se infiltra no interior dos meios, transformando em mídia dados computáveis de qualquer tipo. Em seu formato futuro, olha-se para o universo das telecomunicações e do audiovisual segmentado e se tem dificuldade em distinguir um do outro. As regularidades arqueológicas envolvidas transformam, em um meio de comunicação, a própria atividade de tráfego de dados, que inicialmente modificara a telefonia, sem há algumas décadas se restringir somente a ela. Após a consolidação deste paradigma, presencia-se a metamorfose de qualquer recurso que venha a aderir à representação numérica. Em um extenso processo histórico, do qual este texto descreve parcela decisiva, o digital se move em direção às experiências com o som e a imagem. As tecnologias de informação, ao se transformarem em um tema relativo à cultura, terminam por se encontrar com a indústria cultural, que rejuvenesce. Qualquer um pode se salvar pela intervenção divina; safar-se no mundo da matéria crua é para poucos. 


\section{Referências}

ABTA pede à Anatel que não licencie DTH para teles. Tela Viva, São Paulo, 11 set. 2006. Disponível em: <http://www.telaviva.com.br/11/09/2006/abta-pede-a-anatel-que-naolicencie-dth-para-teles/pt/66345/news.aspx>. Acesso em: 18 out. 2014.

ABTA vai ao Cade contra aquisição da TVA pela Telefônica. Tela Viva, São Paulo, 23 mar. 2007. Disponível em: <http://www.telaviva.com.br/23/03/2007/abta-vai-ao-cade-contraaquisicao-da-tva-pela-telefonica/pt/71796/news.aspx>. Acesso em: 18 jun. 2014.

ANATEL nega à Telemar anuência para adquirir WayTV. Teletime, São Paulo, 19 mar. 2007. Disponível em: <http://www.teletime.com.br/19/03/2007/anatel-nega-a-telemaranuencia-para-adquirir-waytv/tt/71580/news.aspx>. Acesso em: 30 out. 2014.

BALBONTÍN, Patricio Rozas. Privatización, reestructuración industrial y prácticas regulatorias en el sector telecomunicaciones. Santiago de Chile: Cepál, 2005.

BRASIL. Conselho Administrativo de Defesa Econômica Ato de concentração $\mathbf{n}^{\circ}$ 53500.031787/2006 (Telecomunicações de São Paulo S.A. Telesp e Abril Comunicações S.A.). Brasília, 2006.

CARIELLO, Rafael. Fixas perdem e Embratel fica com a Telmex. Folha de S. Paulo, São Paulo, 24 ago. 2004. Disponível em: <http://www1.folha.uol.com.br/fsp/dinheiro /fi2804200402.htm>. Acesso em: 24 jun. 2014.

DREYFUS, Hubert; RABINOW, Paul. Michel Foucault: beyond structuralism and hermeneutics. Chicago: University of Chicago, 1983.

FOUCAULT, Michel. A arqueologia do saber. Rio de Janeiro: Forense Universitária, 1969.

FUOCO, Taís. Para ABTA, atuação da Telefônica no setor de TV paga em São Paulo é "ilegal". Valor Online, 31 out. 2006. Disponível em:

<http://www.valor.com.br/arquivo/522453/para-abta-atuacao-da-telefonica-no-setor-detv-paga-em-sao-paulo-e-ilegal\#ixzz3ASe5Kxyh>. Acesso em: 15 ago. 2014.

GUTTING, Gary. Michel Foucault's archaeology of scientific reason. New York: Cambridge University Press, 1989.

HUHTAMO, Erkki; PARIKKA, Jussi (Org.). Media archaeology: approaches, applications, and implications. Berkeley: University of California, 2011.

JENKINS, Henry. Cultura da convergência: a colisão entre os velhos e novos meios de comunicação. São Paulo: Aleph, 2006.

KITTLER, Friedrich. Optical media. Cambridge: Polity, 1999.

LADEIRA, J. M. Ponto sem retorno? O caso Vivax e a televisão segmentada brasileira. Revista Latinoamericana de Ciencias de la Comunicación, São Paulo, v. 11, n. 21, p. 174-183, 2014. 
LEMOS, André. Cibercultura: tecnologia e vida social na cultura contemporânea. Porto Alegre: Sulina, 2002.

LÉVY, Pierre. Cibercultura. Rio de Janeiro: Editora 34, 1997.

LÉVY, Pierre. Tecnologias da inteligência. Rio de Janeiro: Editora 34, 1990.

LOBATO, Elvira. Telmex quer comprar parte da Net. Folha de S. Paulo, São Paulo, 15 maio 2004. Disponível em: <http://www1.folha.uol.com.br/fsp/dinheiro/fi1505200423.htm>. Acesso em: 28 set. 2014.

LOPES, Maria Immacolata Vassallo de; OROZCO GÓMEZ, Guillermo. Transnacionalização da ficção televisiva nos países ibero-americanos: Obitel 2012. Porto Alegre: Sulina, 2012.

MANOVICH, Lev. Software takes command. New York: Bloomsbury Academic, 2013.

MARISCAL, Judith; RIVERA, Eugenio. Organización industrial y competencia en las telecomunicaciones en América Latina: estrategias empresariales. Santiago de Chile: Cepál, 2005.

MAZZA, Mariana. Anatel aprova DTH da Embratel, com obrigações. Teletime, São Paulo, 24 abr. 2008a. Disponível em: <http://www.teletime.com.br/24/04/2008/anatel-aprova-dthda-embratel-com-obrigacoes/tt/87869/news.aspx>. Acesso em: 2 fev. 2015.

MAZZA, Mariana. Cade aprova com restrições compra da Way TV. Teletime, São Paulo, 4 jun. 2008b. Disponível em: <http://www.teletime.com.br/04/06/2008/cade-aprova-comrestricoes-compra-da-way-tv/tt/89218/news.aspx>. Acesso em: 31 out. 2014.

MERMELSTEIN, André. Net quer novas aquisições para complementar rede. Tela Viva, São Paulo, 1 set. 2008. Disponível em: <http://www.teletime.com.br/01/09/2008/net-quernovas-aquisicoes-para-complementar-rede/tt/92656/news.aspx>. Acesso em: 25 ago. 2009.

OI É AUTORIZADA pela Anatel a prestar serviço de DTH. Tela Viva, São Paulo, 16 set. 2008. Disponível em: <http://www.teletime.com.br/16/09/2008/oi-e-autorizada-pela-anatel-aprestar-servico-de-dth/tt/93174/news.aspx>. Acesso em: 2 fev. 2015.

PARENTE, Edianez. ABTA também quer bloquear Telefônica no DTH. Tela Viva, São Paulo, 30 ago. 2006. Disponível em: <http://www.telaviva.com.br/30/08/2006/abta-tambemquer-bloquear-telefonica-no-dth/pt/66042/news.aspx>. Acesso em: 3 jun. 2014.

PARIKKA, Jussi. What is media archaeology? Cambridge: Polity, 2012.

POSSEBON, Samuel. Anatel aprova entrada da Telefônica na TVA. Tela Viva, São Paulo, 18 jul. 2007a. Disponível em: <http://www.telaviva.com.br/18/07/2007/anatel-aprovaentrada-da-telefonica-na-tva/pt/76020/news.aspx>. Acesso em: 3 mar. 2014.

POSSEBON, Samuel. Assim na Terra como no Céu. Revista Tela Viva, São Paulo, n. 165, p. 14-16, out. 2006. 
POSSEBON, Samuel. Telefônica tem sinal verde para começar DTH. Tela Viva, São Paulo, 21 maio 2007b. Disponível em: <http://www.telaviva.com.br/21/05/2007/telefonica-temsinal-verde-para-comecar-dth/pt/73987/news.aspx>. Acesso em: 3 mar. 2014.

POSSEBON, Samuel. TV por assinatura: 20 anos de evolução. São Paulo: ABTA, 2009.

SANTAELLA, Lúcia. Navegar no ciberespaço: o perfil cognitivo do leitor imersivo. São Paulo: Paulus, 2004.

SHERIDAN, Alan. Michel Foucault: the will to truth. London: Tavistock, 1980.

SMART, Barry. Michel Foucault. Nova York: Routledge, 1985.

TELEMAR compra operadora de TV paga Way por R 132 milhões. Teletime, São Paulo, 27 jul. 2006. Disponível em: <http://www.teletime.com.br/27/07/2006/telemar-compraoperadora-de-tv-paga-way-por-r-132-milhoes/tt/64899/news.aspx>. Acesso em: 28 out. 2014.

TVA consegue liminar contra oposição da ABTA. Tela Viva, São Paulo, 18 abr. 2007. Disponível em: <http://www.telaviva.com.br/18/04/2007/tva-consegue-liminar-contraoposicao-da-abta/pt/72933/news.aspx>. Acesso em: 16 ago. 2014.

ZIELINSKI, Siegfried. Audiovisions: cinema and television as entr'actes in history. Amsterdam: Amsterdam University, 1994.

\title{
Norms, Techniques, Exchanges: Telefónica- Telmex and the Association between Telecommunications-Television in Brazil
}

\begin{abstract}
This paper examines a facet of the audiovisual organization field inside the contemporary Brazil: the progressive presence of telecommunication entrepreneurships in segmented television. Part of the broadcast reconfiguration, this question will be tackled as a particular aspect of convergence. The main goal is to identify how an operation historically associated to the cultural industry becomes just one of those involved with audiovisual. In order to perceive that association will be set as matter of discussion the institutionalization about the presence of Telmex and Telefónica in Brazil through their actions in cable and satellite activities. Looking from a point of view that seeks to contribute to television studies through the proposal of media archeology, the focus of this paper will be the system of dispersion in action, associating juridical regulation, information
\end{abstract}


technologies and material negotiations, as a indicative of a discontinuous process.

\section{Keywords}

Television studies. Media archeology. Convergence.

Recebido em 12/06/2015

Aceito em 15/03/2016 